\title{
Study on the Relationship between Subjective Oral Dryness and Stimulated Saliva or Oral Mucosal Moisture
}

\author{
Fumi Takahashi, DDS, PhD, ${ }^{a}$ Mutsumi Takahashi, DDS, ${ }^{a}$ Shuji Toya, DDS, PhD, ${ }^{b}$ \\ and Osami Morita, DDS, $\mathrm{PhD}^{\mathrm{a}}$ \\ a Department of Complete Denture, The Nippon Dental University School of Life Dentistry at Niigata, Niigata, Japan \\ ${ }^{\mathrm{b}}$ Dry Mouth Clinic, The Nippon Dental University Niigata Hospital, Niigata, Japan
}

\section{Clinical significance}

This study investigated the relationship between subjective oral dryness and stimulated saliva or oral mucosal moisture. Both stimulated saliva and oral mucosal moisture are related to subjective oral dryness, and the Saxon test and the test using an oral moisture checking device are useful for assessing subjective oral dryness.

\begin{abstract}
Purpose: The present study aimed to investigate the relationship between subjective oral dryness and stimulated saliva or oral moisture.

Methods: Twenty-one patients with subjective oral dryness (OD) and 21 healthy adults (HA) were enrolled in the study. The Saxon test was performed by chewing a gauze sponge for 2 minutes. Oral moisture was measured at the lingual mucosa (LM) and buccal mucosa (BM) by using an oral moisture checking device. Group differences in the amount of stimulated saliva and oral moisture were compared using the Mann-Whitney $U$ test and Student's $t$ test.
\end{abstract}

Results: The average amount of salivary secretion in OD and HA in the Saxon test was $0.65 \pm 0.55$ and 2.34 $\pm 1.41 \mathrm{~g} / 2 \mathrm{~min}$, respectively; the difference between the groups was significant $(\mathrm{p}<0.01)$. The oral moisture at the $\mathrm{LM}$ in OD and HA was $27.2 \% \pm 2.9 \%$ and $32.3 \% \pm$ $1.7 \%$, respectively; this difference was significant $(\mathrm{p}<$ 0.01 ). The oral moisture at the BM in OD and HA was $32.6 \% \pm 2.1 \%$ and $34.0 \% \pm 2.2 \%$, respectively; this difference was also significant $(\mathrm{p}<0.05)$.

Conclusion: This study demonstrated that the amount of stimulated saliva became less than $2.00 \mathrm{~g}$ and the moisture at the LM became less than $30.0 \%$ in patients with subjective oral dryness. These results suggest that stimulated saliva and oral moisture are related to sub-

Corresponding to: Dr Fumi Takahashi

Department of Complete Denture, The Nippon Dental

University School of Life Dentistry at Niigata

1-8 Hamaura-cho, Chuo-ku, Niigata-city, Niigata 951-8580,

Japan

Tel: +81-25-267-2500, Fax: +81-25-267-8906

E-mail: fumichan@ngt.ndu.ac.jp

Received on August 24, 2007/ Accepted on December 8, 2007 jective oral dryness; thus, both the Saxon test and the test using an oral moisture checking device are useful for the assessment of subjective oral dryness.

Key words: subjective oral dryness, stimulated saliva, oral mucosal moisture

\section{Introduction}

Xerostomia ${ }^{1}$ causes a decrease in the amount of salivary secretion, which can lead to other symptoms of the oral cavity and pharynx..$^{2-8}$ Many elderly dental patients have subjective oral dryness; hence, it is necessary to evaluate this problem in a clinical setting. To evaluate oral dryness, an easy method is required that can be performed independent of oral function and overall condition..$^{9,10}$

One of the methods to evaluate stimulated saliva is the chewing gum test. However, it is difficult to perform this test in elderly dental patients wearing dentures. The Saxon test, ${ }^{11}$ which is performed by chewing gauze for 2 minutes, easily measures the amount of stimulated saliva. An oral moisture checking device Mucus $^{\circledR}$, Life Co., Saitama, Japan) ${ }^{12}$ measures the oral mucosal moisture within 2 seconds. The Saxon test and the test using the oral moisture checking device can be performed independent of oral function or overall condition. Thus, these tests can facilitate prosthodontic treatment such as denture treatment of patients based on evaluation of their oral dryness.

Some studies have investigated the relationship between subjective oral dryness and unstimulated whole saliva. A few of these studies reported that a relationship exist between subjective oral dryness and unstimulated whole saliva. ${ }^{13-15}$ Another study indicated a weak association between subjective oral dryness and unstimulated whole saliva. ${ }^{16}$ However, the relationship between subjective oral dryness and stimulated saliva or oral mucosal moisture remains unclear. 


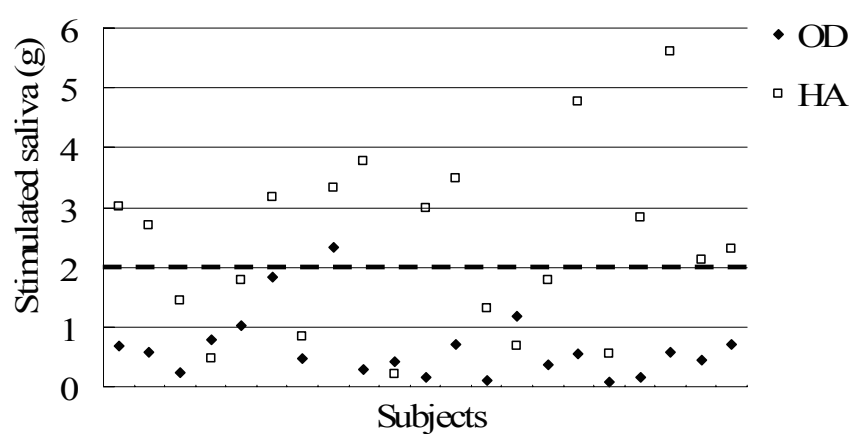

Fig. 1 Stimulated saliva of each subject.

The dotted line indicates the borderline. OD: Patients with subjective oral dryness. HA: Healthy adults

The present study aimed to investigate the relationship between subjective oral dryness and stimulated saliva or oral mucosal moisture. Additionally, the relationship between stimulated saliva and oral mucosal moisture was examined.

\section{Materials and methods}

The study subjects were patients who visited the Nippon Dental University Niigata Hospital. Twenty-one patients with subjective oral dryness (OD: 1 male, 20 females, mean age: $69.3 \pm 10.5$ years) and 21 healthy adults (HA: 1 male, 20 females, mean age: $63.6 \pm 14.8$ years) were enrolled in this study. The Saxon test was performed by chewing a gauze sponge (Kerlix ${ }^{\circledR}$, Kendall Co., Boston, MA) for 2 minutes, and the saliva absorbed in the gauze was collected. ${ }^{17}$

Oral mucosal moisture was measured at the lingual mucosa (LM, the surface of the tongue at $10 \mathrm{~mm}$ from the apex linguae) and buccal mucosa (BM, $10 \mathrm{~mm}$ from the angle of the mouth) using the oral moisture checking device $\left(\right.$ Mucus $^{\circledR}$, Life Co.). For the measurement of LM moisture, the subjects were asked to stick out their tongue, while for the measurement of BM moisture, the outside of the cheek was supported by the operator's finger. ${ }^{12}$ The measurement was repeated 3 times, and the mean value was calculated.

These examinations were performed at a particular time, that is, more than 2 hours after a meal. The study period was December, 2004 to September, 2005.

Group differences in the amount of stimulated saliva and oral mucosal moisture were compared using the Mann-Whitney $U$ test when the data did not show normal distribution and Student's $t$ test when the data showed normal distribution. The

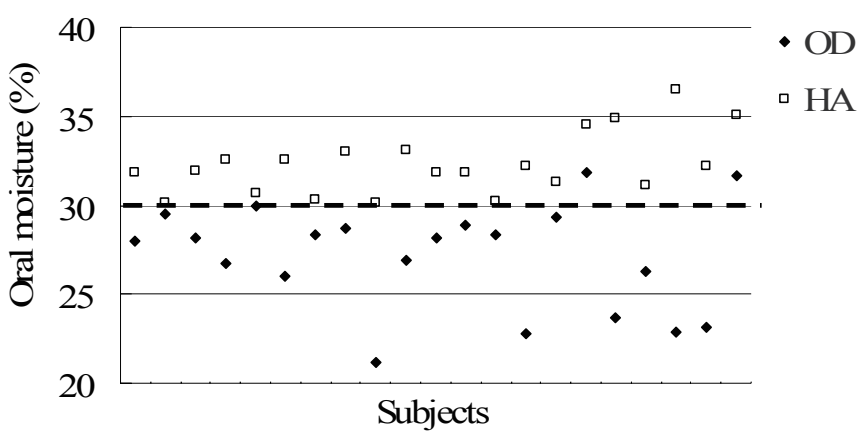

Fig. 2 Oral mucosal moisture of each subject at the LM. The dotted line indicates the borderline. OD: $\mathrm{Pa}-$ tients with subjective oral dryness. HA: Healthy adults

relationship between stimulated saliva and oral mucosal moisture was analyzed by Spearman's rank correlation coefficient because the data did not show normal distribution.

\section{Results}

The amount of stimulated saliva of each subject in the Saxon test is shown in Fig. 1. The average amount of salivary secretion in the OD and HA groups was $0.65 \pm 0.55$ and $2.34 \pm 1.41 \mathrm{~g} / 2 \mathrm{~min}$, respectively; the difference between both the groups was significant $(\mathrm{p}<0.01)$.

The oral mucosal moisture of each subject at the LM is shown in Fig. 2. The average oral mucosal moisture at the LM in the OD and HA groups was $27.2 \% \pm 2.9 \%$ and $32.3 \% \pm 1.7 \%$, respectively; this difference was significant $(\mathrm{p}<0.01)$.

The oral mucosal moisture of each subject at the $\mathrm{BM}$ is shown in Fig. 3. The average oral mucosal moisture at the BM in OD and HA was $32.6 \% \pm$ $2.1 \%$ and $34.0 \% \pm 2.2 \%$, respectively; this difference was also significant $(\mathrm{p}<0.05)$.

The correlation coefficient between stimulated saliva and the oral mucosal moisture at the LM was statistically significant $(r=0.511, p<0.01)$ (Fig. 4). However, no statistical significance was observed for the correlation coefficient between stimulated saliva and oral mucosal moisture at the BM ( $\mathrm{r}=0.136, \mathrm{p}=0.38)$ (Fig. 5). The correlation coefficient between the oral mucosal moisture at the LM and BM was statistically significant ( $\mathrm{r}$ $=0.595, \mathrm{p}<0.01$ ) (Fig. 6).

\section{Discussion}

Saxon test is one of the methods to evaluate the salivary secretory function and can be performed 


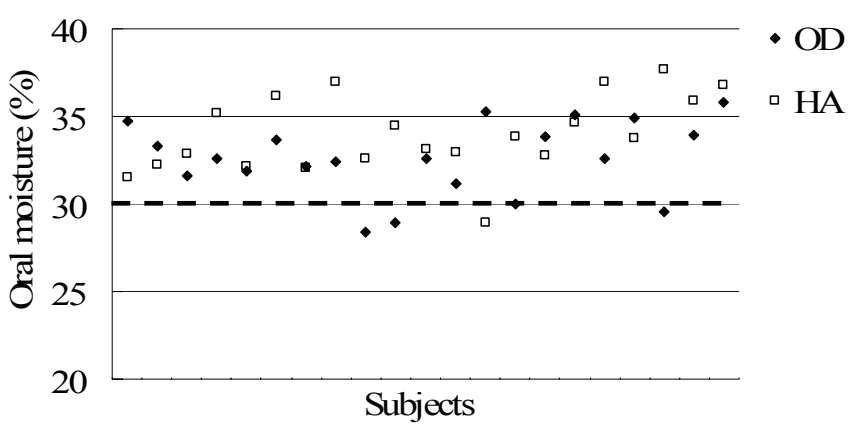

Fig. 3 Oral mucosal moisture of each subject at the $\mathrm{BM}$. The dotted line indicates the borderline. OD: $\mathrm{Pa}^{-}$ tients with subjective oral dryness. HA: Healthy adults

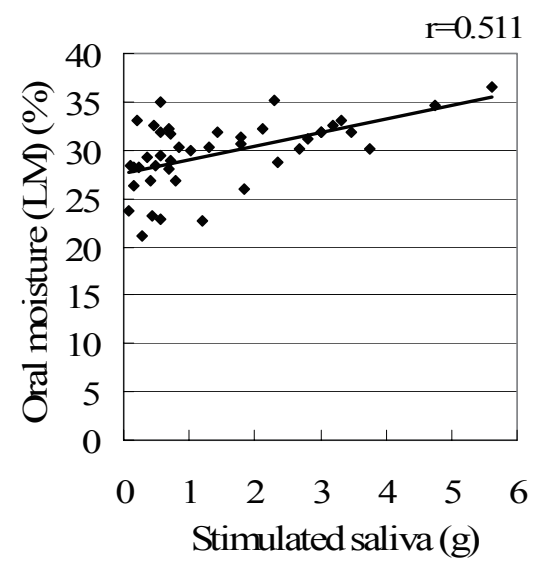

Fig. 5 Relationship between stimulated saliva and the oral mucosal moisture at the BM.

in a patient wearing denture. Xerostomia is diagnosed when the amount of salivary secretion is $2.00 \mathrm{~g} / 2 \mathrm{~min}$ or less. It is unclear whether the measurement period or the operator can cause variations in the measurement value of the Saxon test. Hence, it is necessary to examine these factors that can influence the results of the Saxon test.

The oral moisture checking device used in this study is developed from a skin moisture checking device, which is currently in general use. According to the manufacturer, the oral moisture checking device measures moisture of the epithelium in terms of capacitance. The dielectric constant of water is extremely higher than that of other substances; therefore, the percentage of water in a substance can be determined by measuring the dielectric constant of the substance. The oral moisture checking device measures moisture of a substance by calculating the capacitance from the dielectric constant of the substance. The weight of moisture in the protein membrane is used as

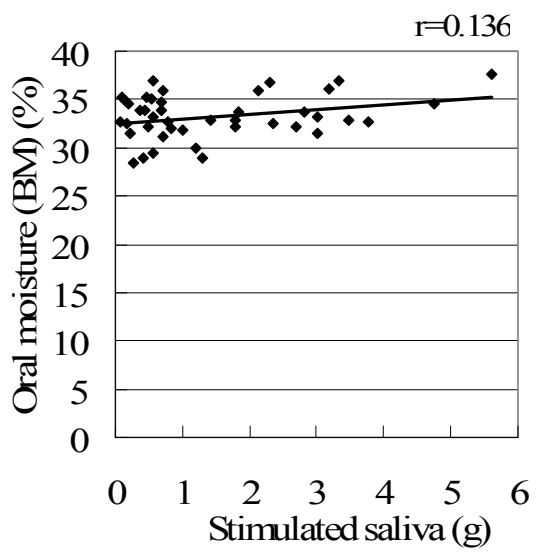

Fig. 4 Relationship between stimulated saliva and the oral mucosal moisture at the LM.

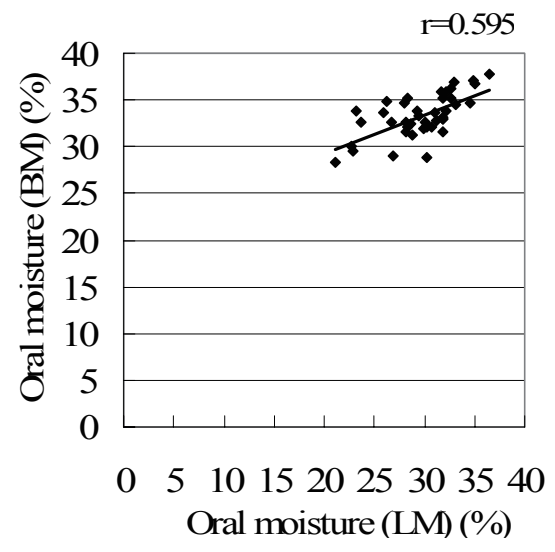

Fig. 6 Relationship between the oral mucosal moisture at the LM and BM.

the standard against which the measured value (\%) is compared. By using the dry weight method, the moisture percentage is calculated as follows: $\mathrm{B} /(\mathrm{A}+\mathrm{B}) \times 100(\%)$, where $\mathrm{A}$ is the weight of the dried protein membrane and $\mathrm{B}$ is the weight of water. The indicated value is reliable because the correlation coefficient against the standard sample between the percentage of the dry weight method and the measured value of the oral moisture checking device is 0.98 .

The oral moisture checking device measures the moisture of the epithelium to a depth of several tens of micrometers within an area of one square centimeter. In general, an oral mucosal moisture level of more than $30 \%$ is normal; $29 \%$ to $30 \%$, borderline; $27 \%$ to $29 \%$, low level of salivary secretion; $25 \%$ to $27 \%$, medium oral dryness; and $25 \%$ or less, severe oral dryness. ${ }^{18}$

In the present study, the amount of stimulated saliva in OD in the Saxon test was less than $2.00 \mathrm{~g} / 2 \mathrm{~min}$. However, the amount of stimulated 
saliva in HA also tended to be less than $2.00 \mathrm{~g} / 2$ min. This suggested that it would be difficult to evaluate subjective oral dryness by the Saxon test alone.

The oral moisture at the LM in OD was less than $30 \%$. On the other hand, the oral moisture at the $\mathrm{BM}$ was more than $30 \%$, which is the normal value. The reason for this difference in the oral moisture levels at the LM and BM is not clear yet; however, it was considered that the structural difference between the $\mathrm{LM}$ and $\mathrm{BM}$ is responsible for this tendency. There is another possibility that the oral moisture checking device could not detect the difference in the moisture at the $\mathrm{BM}$ or that the moisture at the BM was not influenced by oral dryness.

No statistical significance was observed for the correlation coefficient between stimulated saliva and oral mucosal moisture at the BM. This may have resulted due to the almost same level of oral moisture at the BM in OD and HA. Therefore, the $\mathrm{BM}$ as the measurement part is not suitable for the determination of subjective oral dryness.

The present study demonstrated that the amount of stimulated saliva became less than 2.00 $\mathrm{g} / 2$ min and the moisture at the LM became less than $30.0 \%$ in patients with subjective oral dryness. These results suggest that subjective oral dryness can be examined using both the Saxon test and the test using the oral moisture checking device. However, the examination of oral dryness by the Saxon test alone would be difficult. Therefore, for the determination of oral dryness, it is necessary to perform both the Saxon test and the test using the oral moisture checking device.

This study also clarified that stimulated saliva was significantly correlated with the oral mucosal moisture at the LM.

In the future study, the influence of medicines and diseases will be evaluated using the Saxon test and the oral moisture checking device.

\section{References}

1. Sreebny LM, Valdini A. Xerostomia. A neglected symptom. Arch Intern Med 1987; 147: 13331337.

2. Fox PC, van der Ven PF, Sonies BC et al. Xerostomia: evaluation of a symptom with increasing significance. J Am Dent Assoc 1985; 110: 519525.

3. Edgerton M, Tabak LA, Levine MJ. Saliva: a significant factor in removable prosthodontic treat- ment. J Prosthet Dent 1987; 57: 57-66.

4. Sreebny LM, Valdini A. Xerostomia. Part 1: relationship to other oral symptoms and salivary gland hypofunction. Oral Surg Oral Med Oral Pathol 1988; 66: 451-458.

5. Mandel ID. The role of saliva in maintaining oral homeostasis. J Am Dent Assoc 1989; 119: 298304.

6. Niedermeier WH, Kramer R. Salivary secretion and denture retention. J Prosthet Dent 1992; 67: 211-216.

7. Sinclair GF, Frost PM, Walter JD. New design for an artificial saliva reservoir for the mandibular complete denture. J Prosthet Dent 1996; 75: 276280.

8. Diaz AAM, Marek CA. The impact of saliva on patient care: a literature review. J Prosthet Dent 2002; 88: 337-343.

9. Walff A, Herscovici D, Rosenberg M. A simple technique for the determination of salivary gland hypofunction. Oral Surg Oral Med Oral Pathol Oral Radiol Endod 2002; 94: 175-178.

10. Chen A, Wai Y, Lee L et al. Using the modified Schirmer test to measure mouth dryness: a preliminary study. J Am Dent Assoc 2005; 136: 164170 .

11. Peter FK, Margaret EW. A quantitative test for xerostomia. The Saxon test, an oral equivalent of the Schirmer test. Arthritis Rheum 1985; 28: 1128-1132.

12. Takahashi F, Koji T, Morita O. The usability of an oral moisture checking device (Mucus $\left.{ }^{\circledR}\right)$. J Jpn Prosthodont Soc 2005; 49-113: 194.

13. Lundström IM, Lundström FD. Subjective and clinical oral symptoms in patients with primary Sjögren's syndrome. Clin Exp Rheumatol 1995; 13: 725-731.

14. Pedersen AM, Reibel J, Nauntofte B. Primary Sjögren's syndrome (pSS): subjective symptoms and salivary findings. Oral Pathol Med 1999; 28: 303-311.

15. Márton K, Boros I, Varga G et al. Evaluation of palatal saliva flow rate and oral manifestations in patients with Sjögren's syndrome. Oral Dis 2006; 12: 480-486.

16. Hay EM, Thomas E, Pal B et al. Weak association between subjective symptoms of and objective testing for dry eyes and dry mouth: results from a population based study. Ann Rheum Dis 1998; 57: 20-24.

17. Takahashi F, Koji T, Morita O. Evaluation of the usability of modified saxon test. Prosthodont Res Pract 2003; 2: 82-87.

18. Kakinoki Y, Nakamura S, Koseki T. The practice of the test of saliva and the point of diagnosis. Dental Outlook 2004; 103: 47-52. (in Japanese) 